\title{
A retrospective study of docetaxel and bevacizumab as a second- or later-line chemotherapy for non-small cell lung cancer
}

\author{
KOICHI KURISHIMA ${ }^{1}$, HIROKO WATANABE ${ }^{2}$, HIROICHI ISHIKAWA ${ }^{1}$, \\ HIROAKI SATOH $^{3}$ and NOBUYUKI HIZAWA ${ }^{2}$ \\ ${ }^{1}$ Division of Respiratory Medicine, Tsukuba Medical Center Hospital, Tsukuba, Ibaraki 305-8558; \\ ${ }^{2}$ Division of Respiratory Medicine, Faculty of Medicine, University of Tsukuba, Tsukuba, Ibaraki 305-8575; \\ ${ }^{3}$ Division of Respiratory Medicine, Mito Medical Center, University of Tsukuba, Mito, Ibaraki 310-0015, Japan
}

Received October 11, 2016; Accepted March 24, 2017

DOI: $10.3892 /$ mco.2017.1282

\begin{abstract}
Comparative results of second- or later-line bevacizumab plus docetaxel and docetaxel alone for patients with NSCLC have never been reported. In order to evaluate the combined effect of bevacizumab and docetaxel as secondor later-line chemotherapy for NSCLC, a retrospective study was performed. Between November 2009 and April 2016, the medical records of all the patients $<75$ years old who were treated with docetaxel $\left(60 \mathrm{mg} / \mathrm{m}^{2}\right.$, dayl, q3 or 4 weeks) plus bevacizumab (15 mg/kg, day $1, \mathrm{q} 3$ or 4 weeks) as a second- or later-line chemotherapy were reviewed. Complete data sets were obtained from 15 patients treated with docetaxel plus bevacizumab, and 55 patients treated with docetaxel alone. The overall response rate to docetaxel plus bevacizumab therapy was 26.7 , and $53.3 \%$ of these patients had stable disease (SD), amounting to a disease control rate of $80.0 \%$. On the other hand, the overall response rate to docetaxel alone therapy was 9.1 , and $38.2 \%$ of these patients had SD, amounting to a disease control rate of $47.3 \%$. All the patients treated with docetaxel plus bevacizumab therapy had grade 3 or 4 'neutropenia' or 'febrile neutropenia', which developed in 100 and $26.7 \%$ of patients, respectively. The rates of these adverse events in patients treated with docetaxel alone were 63.6, and $10.9 \%$, respectively. The mean progression free survival (PFS) in patients treated with docetaxel plus bevacizumab and that of patients with docetaxel alone was 5.9 and 2.1 months, respectively. There was a non-significant tendency towards a difference in survival between the two treatment groups $(\mathrm{P}=0.081, \log$-rank test). The possibility of improvement of response and prolongation of PFS in patients treated with second- or later line docetaxel and bevacizumab
\end{abstract}

Correspondence to: Dr Hiroaki Satoh, Division of Respiratory Medicine, Mito Medical Center, University of Tsukuba, Miya-machi 3-2-7, Mito, Ibaraki 310-0015, Japan

E-mail: hirosato@md.tsukuba.ac.jp

Key words: docetaxel, bevacizumab, second-line chemotherapy, NSCLC chemotherapy may be suggested in this study. However, the higher risk of febrile neutropenia must be noted for this combination of drugs.

\section{Introduction}

Bevacizumab is a humanized monoclonal antibody that inhibits vascular endothelial growth factor (VEGF) activity (1). When it is used in combination with cytotoxic drugs, high clinical utility is predicted for many cancer types including non-small cell lung cancer (NSCLC) $(2,3)$. Evidence for its efficacy when used as an additional drug in first-line chemotherapy for NSCLC has been produced by numerous randomized phase III clinical trials $(2,3)$. Ramucirumab, a new anti-VEGF antibody, combined with docetaxel, has recently been introduced as a second-line chemotherapy for recurrent $\operatorname{NSCLC~}(4,5)$. Therefore, it is of importance to determine which is a more effective treatment, bevacizumab or ramucirumab, in combination with docetaxel, as a second- or later-line chemotherapy for patients with NSCLC. To the best of our knowledge, there have been no clinical trials that compared first-line bevacizumab plus docetaxel and ramucirumab plus docetaxel, In addition, the results of a comparison between second-line bevacizumab plus docetaxel and docetaxel alone for patients with NSCLC have never been reported. In order to evaluate the combined effect of bevacizumab and docetaxel as a second- or later-line chemotherapy for NSCLC, a retrospective study was performed.

\section{Patients and methods}

Patients and treatments. Patients with non-small cell lung cancer were admitted to three tertiary hospitals (Tsukuba University Hospital, Tsukuba Medical Center Hospital, and Mito Medical Center, University of Tsukuba, Tsukuba, Japan) between November 2009 and April 2016. The medical records of all the patients $<75$ years old, who were treated with docetaxel $\left(60 \mathrm{mg} / \mathrm{m}^{2}\right.$, day $1, \mathrm{q} 3$ or 4 weeks) plus bevacizumab $(15 \mathrm{mg} / \mathrm{kg}$, day $1, \mathrm{q} 3$ or 4 weeks) as a second- or later-line chemotherapy were retrospectively reviewed. The clinical data in these patients were compared with those in patients $<75$ years old who were treated with docetaxel $\left(60 \mathrm{mg} / \mathrm{m}^{2}\right.$, day $1, \mathrm{q} 3$ or 4 weeks) alone 
as a second- or later-line chemotherapy during the same study period. All patients were required to have had a pathological or cytological diagnosis of NSCLC. Pathological diagnosis of lung cancer was defined by the World Health Organization classification (6). A tumor-node-metastasis staging (7) procedure using head computed tomography (CT) or magnetic resonance imaging, bone scans and ultrasonography and/or CT of the abdomen was performed for all patients prior to starting bevacizumab treatment. Patient demographic data at the time of bevacizumab therapy (age, sex, smoking history, histology and stage) and objective tumor response were obtained. The tumor response was evaluated as complete response (CR), partial response (PR), stable disease (SD), progressive disease (PD) or not evaluable (NE), according to the Response Evaluation Criteria in Solid Tumors (8). Toxicity was graded according to the National Cancer Institute Common Toxicity Criteria, version 3.0 (9). This observational study conformed to the Ethical Guidelines for Clinical Studies issued by the Ministry of Health, Labor and Welfare of Japan. Informed consent was obtained from patients for their inclusion in this study. Analysis of the medical records of lung cancer patients was approved by the Ethics Committee of Mito Medical Center, University of Tsukuba Hospital (NO 16-19).

Statistical analysis. Differences in proportions between 2 independent groups were compared by the $\chi^{2}$ test. Survival probability was estimated with the Kaplan-Meier method and compared using the log-rank test. All statistical analysis was conducted using SPSS 10.1 for Windows (SPSS Corp., Chicago, IL, USA). $\mathrm{P}<0.05$ was considered to indicate a statistically significant difference.

\section{Results}

Patient characteristics. Complete data sets were obtained from 15 patients treated with docetaxel plus bevacizumab, and 55 patients treated with docetaxel alone. The patient characteristics are listed in Table I. With regards to age, sex, performance status, and pathology, there were no statistically significant differences between the groups. The median treatment line of docetaxel plus bevacizumab, docetaxel alone was third-line in the two treatment groups. The mean number of courses of docetaxel plus bevacizumab was 3.2 (range, 1-15), and that of docetaxel alone was 3.1 (range, 1-13). Dose reduction was performed in $9(33.3 \%)$ of the patients treated with docetaxel plus bevacizumab, and in $25(45.5 \%)$ of those treated with docetaxel alone.

Response to treatment. The overall response rate to docetaxel plus bevacizumab therapy was $26.7 \%$ [0 CR; 4 PR; $95 \%$ confidence interval (CI), 4.3-49.0\%), and $53.3 \%$ of these patients had SD, amounting to a disease control rate of $80.0 \%$. On the other hand, the overall response rate to docetaxel alone therapy was $9.1 \%$ (0 CR; 5 PR; 95\% CI, 1.5-16.7\%), and 38.2\% of these patients had $\mathrm{SD}$, amounting to a disease control rate of $47.3 \%$.

Toxicity. Table II presents the adverse events associated with docetaxel plus bevacizumab therapy. All the patients treated with docetaxel plus bevacizumab therapy had grade 3 or 4

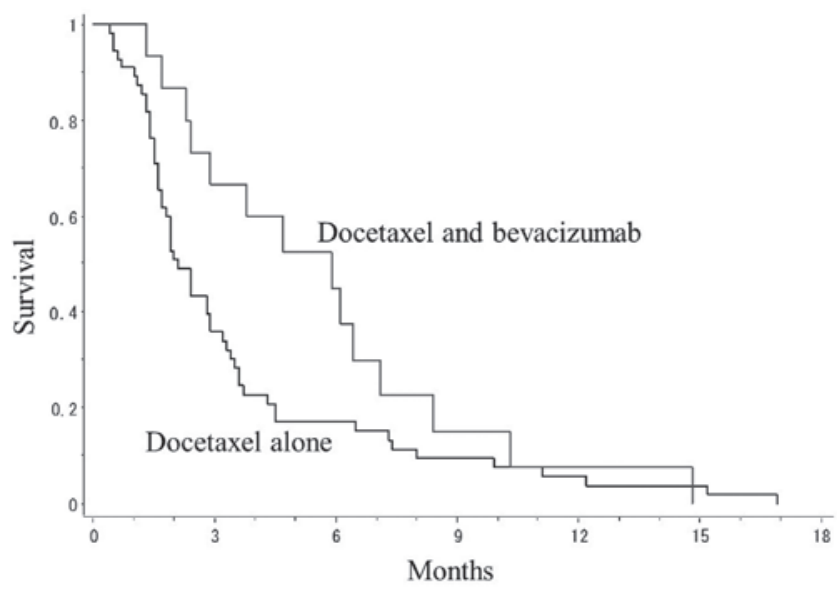

Figure 1. PFS curves of patients treated with docetaxel plus bevacizumab and that of patients with docetaxel alone. A tendency towards a statistically significant difference in survival was noted between the two treatment groups $(\mathrm{P}=0.081, \log$-rank test).

'neutropenia' or 'febrile neutropenia', which developed in $100 \%$ and $26.7 \%$ of patients, respectively. The rates of these adverse events in patients treated with docetaxel alone were $63.6 \%$, and $10.9 \%$, respectively.

Survival analysis. Fig. 1 presents PFS curves of patients treated with docetaxel plus bevacizumab and patients treated with docetaxel alone. The mean PFS in patients treated with docetaxel plus bevacizumab and that of patients with docetaxel alone was 5.9 and 2.1 months, respectively. There was a non-significant tendency towards a difference in survival between the two treatment groups $(\mathrm{P}=0.081$, log-rank test $)$.

\section{Discussion}

Docetaxel, pemetrexed and erlotinib have been recommended as second-line chemotherapy for NSCLC in clinical practice (3). However, there have been insufficient results to comprehensively evaluate their efficacy. Bevacizumab is a monoclonal antibody against VEGF; in combination with cytotoxic agents, its efficacy in improvement of response and prolongation of PFS has been demonstrated $(2,3)$. In addition, the usefulness of bevacizumab in patients with colon cancer beyond PD has been reported (10). The results of clinical trials of second-line docetaxel and ramucirumab for patients with NSCLC have been demonstrated $(4,5)$. Therefore, it is of importance to determine which is the most effective drug, bevacizumab or ramucirumab, in combination with docetaxel, as a second- or later-line chemotherapy for patients with NSCLC. To the best of our knowledge, there have been no clinical trials that compared first-line bevacizumab plus docetaxel and ramucirumab plus docetaxel, In addition, comparative results of second-line bevacizumab plus docetaxel vs. docetaxel alone for patients with NSCLC have not been reported. However, there have been several studies of the efficacy of chemotherapy for patients with recurrent NSCLC. In the JMEI trial, which compared the efficacy of docetaxel and pemetrexed, the response rate (RR) and PFS were $9.0 \%$ and 3 months, and $11.5 \%$ and 3.1 months, respectively (11). The TAILOR trial with erlotinib therapy revealed 
Table I. Comparison of clinicopathological features between patients treated with docetaxel plus bevacizumab and with docetaxel alone.

Variables

Patients treated with docetaxel and bevacizumab

Number of patients

Age, years (median, range)

Male: female

Performance status

$$
\text { 0-1:2-4, N (\%) }
$$

Pathology

Ad: LA, N (\%)

Treatment line of DOC-containing therapy (median, range)

Number of treatment courses, mean (range)

Dose reduction present/absent, N (\%)

55
$62(35-74)$
$39: 16$
$50(90.9): 5(9.1)$
$52(94.5): 3(5.5)$
$3(2-6)$
$3.2(1-13)$
$25(45.5) / 30(54.5)$

Patients treated with docetaxel alone

15

$63(40-75)$

$8: 7$

$13(86.7): 2(13.3)$

$$
\begin{gathered}
15(100): 0(0) \\
3(2-8) \\
5.3(1-15) \\
5(33.3) / 10(66.7)
\end{gathered}
$$

\begin{tabular}{|c|c|c|}
\hline Variables & $\begin{array}{c}\text { Patients treated with } \\
\text { docetaxel and bevacizumab, } \mathrm{N}(\%)\end{array}$ & $\begin{array}{c}\text { Patients treated with } \\
\text { docetaxel alone, } \mathrm{N}(\%)\end{array}$ \\
\hline Number of patients & 15 & 55 \\
\hline \multicolumn{3}{|l|}{ Response } \\
\hline Complete response & $0(0)$ & $0(0)$ \\
\hline Partial response & $4(26.7)$ & $5(9.1)$ \\
\hline Stable disease & $8(53.3)$ & $21(38.2)$ \\
\hline Progressive disease & $3(20)$ & $29(52.7)$ \\
\hline Complete response + partial response & $4(26.7)$ & $5(9.1)$ \\
\hline Complete response + partial response + stable disease & $12(80)$ & $26(47.3)$ \\
\hline
\end{tabular}

$\mathrm{AD}$, adenocarcinoma; LA, large cell carcinoma; DOC, docetaxel.

\begin{tabular}{|c|c|c|c|c|}
\hline \multirow{2}{*}{$\begin{array}{l}\text { Toxicity } \\
\text { Grade }\end{array}$} & \multicolumn{2}{|c|}{$\begin{array}{l}\text { Patients treated with docetaxel } \\
\text { and bevacizumab, } \mathrm{N}(\%)\end{array}$} & \multicolumn{2}{|c|}{$\begin{array}{c}\text { Patients treated with docetaxel } \\
\text { alone, } \mathrm{N}(\%)\end{array}$} \\
\hline & IV & III/IV & IV & III/IV \\
\hline Leukopenia & $4(7.3)$ & $29(52.2)$ & $2(13.3)$ & $14(93.3)$ \\
\hline Neutropenia & $19(34.5)$ & $35(63.6)$ & $13(86.7)$ & $15(100)$ \\
\hline Febrile neutropenia & $0(0)$ & $6(10.9)$ & $0(0)$ & $4(26.7)$ \\
\hline Hemoglobin & $1(1.8)$ & $7(12.7)$ & $0(0)$ & $0(0)$ \\
\hline Nausea & $0(0)$ & $3(5.9)$ & $0(0)$ & $0(0)$ \\
\hline Diarrhea & $0(0)$ & $1(1.8)$ & $0(0)$ & $0(0)$ \\
\hline Stomatitis & $0(0)$ & $1(1.8)$ & $0(0)$ & $0(0)$ \\
\hline Hyponatremia & $0(0)$ & $1(1.8)$ & $0(0)$ & $0(0)$ \\
\hline Lung toxicity & $0(0)$ & $1(1.8)$ & $0(0)$ & $0(0)$ \\
\hline
\end{tabular}

Table II. Comparison of clinicopathological features between patients treated with docetaxel plus bevacizumab and with docetaxel alone.

Table III. Comparison of toxicity in patients treated with docetaxel plus bevacizumab and with docetaxel alone.

that the RR and PFS were $3.0 \%$ and 2.4 months (12). The Lux-Lung-4 trial with afatinib, the RR and PFS were $8.2 \%$ and 4.4 months (13). The NCCTG-SWOG N0426 trial with pemetrexed and bevacizumab revealed that the RR and PFS 
were $10.4 \%$ and 4.0 months (14). Herbst et al (15) reported a difference between patients treated with chemotherapy alone with pemetrexed or docetaxel and those treated with bevacizumab plus chemotherapy with pemetrexed or docetaxel; the median PFS and 6-month survival rate in the former group of patients was 3 months and $21.5 \%$, respectively. On the on the other hand, in the latter group of patients these values were 4.8 months and $30.5 \%$, respectively (15). In the present study, in 15 patients treated with docetaxel and bevacizumab, the RR and PFS were $26.7 \%$ and 5.9 months, which appears comparable to the aforementioned previous reports.

The current study has certain limitations. The retrospective design without a large number of patients limited the generalizability of the results. This was not a randomized controlled trial and the indications of chemotherapy, whether docetaxel and bevacizumab or docetaxel only, were clearly determined. As a result, there was no statistical significant difference in clinical characteristics between the two treatment groups of patients. In the two treatment groups, the median line of docetaxel-containing chemotherapy was third-line. However, the results obtained in this study were those in unselected consecutive patients in daily clinical practice.

The present retrospective study was performed to evaluate the clinical efficacy of docetaxel and bevacizumab as a secondor later-line chemotherapy for NSCLC. To exclude the effect of uncertain factors on the results, the efficacy and adverse events of docetaxel and bevacizumab therapy were evaluated in patients $<75$ years old.

In conclusion, the possibility of an improvement of response and prolongation of PFS in patients receiving secondor later-line docetaxel and bevacizumab chemotherapy may have been suggested by this study. However, the higher risk of febrile neutropenia must be noted for this combination of drugs.

\section{References}

1. Khosravi Shahi P and Fernández Pineda I: Tumoral angiogenesis: Review of the literature. Cancer Invest 26: 104-108, 2008.

2. Behera M, Pillai RN, Owonikoko TK, Kim S, Steuer C, Chen Z, Saba NF, Belani CP, Khuri FR and Ramalingam SS: Bevacizumab in combination with taxane versus non-taxane containing regimens for advanced/metastatic nonsquamous non-small-cell lung cancer: A systematic review. J Thorac Oncol 10: 1142-1147, 2015

3. Carnio S, Novello S, Mele T, Levra MG and Scagliotti GV: Extending survival of stage IV non-small cell lung cancer. Semin Oncol 41: 69-92, 2014.

4. Du L and Morgensztern D: Chemotherapy for Advanced-Stage Non-Small Cell Lung Cancer. Cancer J 21: 366-370, 2015.
5. Cooper MR, Binkowski C, Hartung J and Towle J: Profile of ramucirumab in the treatment of metastatic non-small-cell lung cancer. Onco Targets Ther 9: 1953-1960, 2016.

6. Travis WD, Brambilla E, Noguchi M, Nicholson AG, Geisinger KR, Yatabe Y, Beer DG, Powell CA, Riely GJ, Van Schil PE, et al: International association for the study of lung cancer/american thoracic society/european respiratory society international multidisciplinary classification of lung adenocarcinoma. J Thorac Oncol 6: 244-285, 2011.

7. Shepherd FA, Crowley J, Van Houtte P, Postmus PE, Carney D, Chansky K, Shaikh Z and Goldstraw P; International Association for the Study of Lung Cancer International Staging Committee and Participating Institutions: The International Association for the Study of Lung Cancer lung cancer staging project: Proposals regarding the clinical staging of small cell lung cancer in the forthcoming (seventh) edition of the tumor, node, metastasis classification for lung cancer. J Thorac Oncol 2: 1067-1077, 2007.

8. Eisenhauer EA, Therasse P, Bogaerts J, Schwartz LH, Sargent D, Ford R, Dancey J, Arbuck S, Gwyther S, Mooney M, et al: New response evaluation criteria in solid tumours: Revised RECIST guideline (version 1.1). Eur J Cancer 45: 228-247, 2009.

9. Trotti A, Colevas AD, Setser A, Rusch V, Jaques D, Budach V, Langer C, Murphy B, Cumberlin R, Coleman CN and Rubin P: CTCAE v3.0: Development of a comprehensive grading system for the adverse effects of cancer treatment. Semin Radiat Oncol 13: 176-181, 2003.

10. Pohl M and Schmiegel W: Therapeutic Strategies in Diseases of the Digestive Tract-2015 and Beyond Targeted Therapies in Colon Cancer Today and Tomorrow. Dig Dis 34: 574-579, 2016.

11. Hanna N, Shepherd FA, Fossella FV, Pereira JR, De Marinis F, von Pawel J, Gatzemeier U, Tsao TC, Pless M, Muller T, et al: Randomized phase III trial of pemetrexed versus docetaxel in patients with non-small-cell lung cancer previously treated with chemotherapy. J Clin Oncol 22: 1589-1597, 2004.

12. Garassino MC, Martelli O, Broggini M, Farina G, Veronese $S$, Rulli E, Bianchi F, Bettini A, Longo F, Moscetti L, et al: Erlotinib versus docetaxel as second-line treatment of patients with advanced non-small-cell lung cancer and wild-type EGFR tumours (TAILOR): A randomised controlled trial. Lancet Oncol 14: 981-988, 2013.

13. Katakami N,Atagi S, Goto K, Hida T, Horai T, Inoue A, Ichinose Y, Koboyashi K, Takeda K, Kiura K, et al: LUX-Lung 4: A phase II trial of afatinib in patients with advanced non-small-cell lung cancer who progressed during prior treatment with erlotinib, gefitinib, or both. J Clin Oncol 31: 3335-3341, 2013.

14. Adjei AA, Mandrekar SJ, Dy GK, Molina JR, Adjei AA, Gandara DR, Ziegler KL, Stella PJ, Rowland KM Jr, Schild SE and Zinner RG: Phase II trial of pemetrexed plus bevacizumab for second-line therapy of patients with advanced non-small-cell lung cancer: NCCTG and SWOG study N0426. J Clin Oncol 28: 614-619, 2010.

15. Herbst RS, O'Neill VJ, Fehrenbacher L, Belani CP, Bonomi PD, Hart L, Melnyk O, Ramies D, Lin M and Sandler A: Phase II study of efficacy and safety of bevacizumab in combination with chemotherapy or erlotinib compared with chemotherapy alone for treatment of recurrent or refractory non-small-cell lung cancer. J Clin Oncol 25: 4743-4750, 2007. 